\title{
The effects of familiar size on judgments of size and distance: An interaction of viewing attitude with spatial cues
}

\author{
ATSUKI HIGASHIYAMA \\ University of Osaka Prefecture, Osaka, Japan
}

\begin{abstract}
Two hypotheses about the effects of familiar size on judgments of size and distance, the cueconflict hypothesis and the viewing-attitude hypothesis, were examined. In Experiment 1, observers estimated the size and distance of familiar targets with apparent or assumptive instructions under three different spatial cue conditions. In Experiment 2, observers performed tasks similar to those of Experiment 1 with no specific instructions. The main results were: (1) Assumptive instructions facilitate the effects of familiar size in both size and distance judgments, but reducing spatial cues does not, and (2) viewing attitude changes from the apparent to the assumptive when available spatial cues are reduced. Thus, it was concluded that the viewingattitude hypothesis gives a better account of the effects of familiar size, but that the cue-conflict hypothesis cannot be abandoned, because the number of conflicting cues contributes to the formation of viewing attitude.
\end{abstract}

Two hypotheses have been proposed to account fot the effectiveness of object familiarity on size and distance perception. Schiffman (1967), Predebon, Wenderoth, and Curthoys (1974), and Fitzpatrick, Pasnak, and Tyer (1982) argued that the familiar size of an object has an increasingly great effect on perceived size and distance as the number of other spatial cues conflicting with familiar size decreases. For example, in a reduced-cue condition in which familiar size is the only possible cue, it will be a powerful determiner of visual extents, whereas in a natural fullcue situation, its effects are inhibited, because other cues are more informative and reliable. However, this cue-conflict hypothesis leaves open the question of whether the overt responses of size and distance induced by familiar size reflect perceptual properties of the visual system. Schiffman and Predebon et al. suggested that the effects of familiar size were perceptual, but Gogel (1981) has asserted that when a familiar object is perceived as larger or smaller than normal under a reduced-cue condition, the off-sized judgment can provide a cognitive modification of distance.

An alternative hypothesis is that familiar size is effective as a function of viewing attitude, which is formed through enhancement of the object connotation of stimulus targets (Ono, 1969), labeling of neutral targets with the names of familiar objects (Baird, 1963; Hastorf, 1950), or communication of

We would like to thank Martha Teghtsoonian and an anonymous reviewer for their editorial assistance and helpful suggestions on an earlier version of this paper. Requests for reprints should be sent to Atsuki Higashiyama, Psychology Laboratory, University of Osaka Prefecture, Mozu-umemachi, Sakai, Osaka 591, Japan. size information in the form of visual or haptic representation (Coltheart, 1969, 1970; Higashiyama, 1982; Park \& Michaelson, 1974). This hypothesis posits that familiar size influences overt responses of size and distance as a cognitive bias rather than as a perceptual determinant. A series of studies by Gogel and his associates (Gogel, 1969, 1976, 1977, 1981; Gogel \& Newton, 1969; Mershon \& Gogel, 1975) have provided support for the viewing-attitude hypothesis.

The present study consisted of two experiments that were designed to examine those two hypotheses. In Experiment 1, observers made verbal judgments of the size and distance of familiar objects in three conditions (monocular, binocular, and full-cue), which differed in the number of spatial cues available. The observers judged under two sets of instructions, one of which encouraged them to ignore familiar size information ("apparent" instructions) and the other of which encouraged them to utilize such information ("assumptive" instructions), in making their judgments.

Figure 1 illustrates the predictions from the two hypotheses in the situation in which different familiar objects with the same visual angle are presented at a constant viewing distance. The cue-conflict hypothesis predicts that familiar size will have its greatest effects in the condition with fewest spatial cues and its least effects in the condition with most cues; thus, it predicts an interaction between familiar size and cue condition. These predictions are shown in the two top panels of Figure 1, where size or distance estimates are plotted as a function of familiar size with spatial cue condition and instructions as parameters. The viewing-attitude hypothesis predicts that the effects of familiar size depend on the observer's 


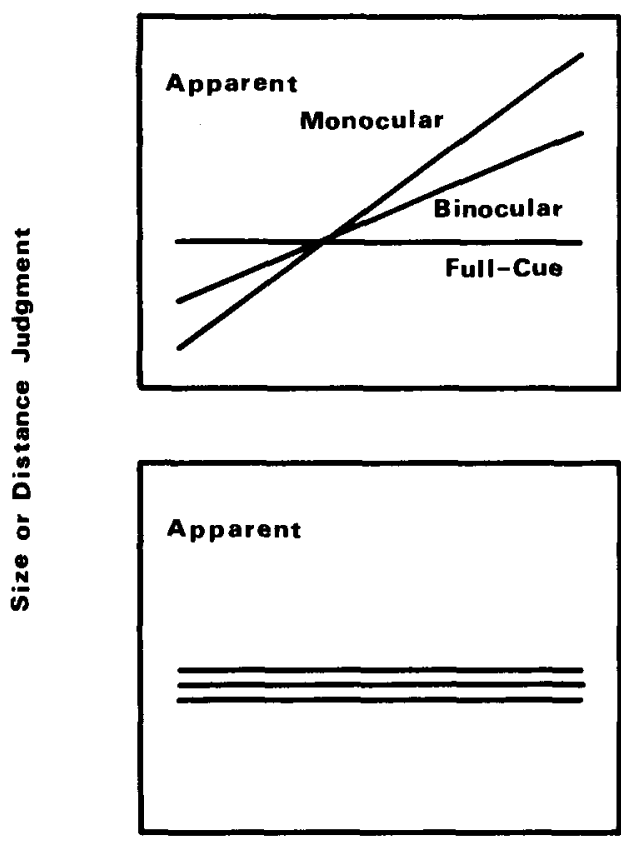

Familiar Size
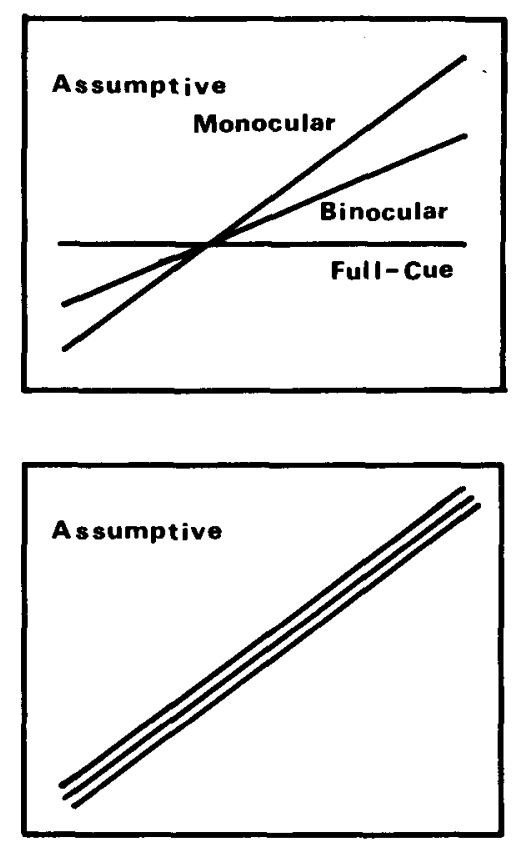

Familiar Size

Figure 1. Predictions of size or distance judgments from the cue-conflict hypothesis and the viewing-attitude hypothesis when familiar objects with the same visual angle are presented at a constant viewing distance. The two top panels: The cue-conflict hypothesis predicts an interaction of familiar size with cue condition. The two bottom panels: The viewing-attitude hypothesis predicts an interaction of familiar size with instructions.

cognitive strategy. If instructions determine this strategy, then the interaction between familiar size and instructions should be significant. The predictions from the viewing-attitude hypothesis are illustrated in the two bottom panels of Figure 1.

The two hypotheses are not mutually exclusive; it is possible that instructions to use familiar size information have the strongest effect when the fewest cues are available. In that case, one would expect a threeway interaction between familiar size, cue condition, and instructions.

In Experiment 2, the observers performed tasks similar to those of Experiment 1, but received no specific instructions; after estimating size and distance, they were required to describe the viewing attitude they had taken spontaneously. This experiment was also a test of the two hypotheses. The cueconflict hypothesis predicts that the effects of familiar size increase with decreasing spatial cues, independently of the observer's viewing attitude. The viewing-attitude hypothesis predicts that the effects of familiar size depend on the observer's viewing attitude, not on the number of conflicting cues.

It was felt, furthermore, that the outcomes of Experiment 2 would be useful in determining how viewing attitude and the number of conflicting cues were causally related to the effects of familiar size. A possible outcome would be that viewing attitude did not change depending on the number of conflicting cues, suggesting that both viewing attitude and cue condition independently influenced the effects of familiar size. Another possibility was that viewing attitude changed as a function of spatial cue condition, indicating that spatial cue information influenced the effects of familiar size through the formation of viewing attitude. In fact, no one had tested whether or not the reduction of available spatial cues had any effect on the formation of viewing attitude.

\section{EXPERIMENT 1}

\section{Method}

Observers. One hundred and eighty students volunteered to serve as observers. All observers had normal or corrected visual acuity.

Apparatus. Figure 2 shows a schematic top-view diagram of the apparatus, which consisted of two similar visual alleys, $A_{1}$ and $A_{2}(22 \mathrm{~cm}$ high $\times 21 \mathrm{~cm}$ wide $\times 150 \mathrm{~cm}$ long), and a viewing box ( $54 \mathrm{~cm}$ high $\times 30.5 \mathrm{~cm}$ wide $\times 30.5 \mathrm{~cm}$ long) with a halfmirror placed at 45 deg against a viewing window. For alley $A_{1}$, a sheet of frosted glass, placed at a viewing distance of $106 \mathrm{~cm}$ from the observer, was used as a screen on which familiar stimulus targets were rear-projected by a Cabin projector. For alley $\mathrm{A}_{2}$, a sheet of frosted glass, placed at a viewing distance of $159 \mathrm{~cm}$ from the observer, was illuminated from behind by a white light bulb. Alley $A_{1}$ was used only under the full-cue condition (see below). The walls and floors of the alleys were covered with black flocked paper, except that the floors of $A_{2}$ consisted of a lateral striped pattern of red and white rectangles. The ceilings of the 


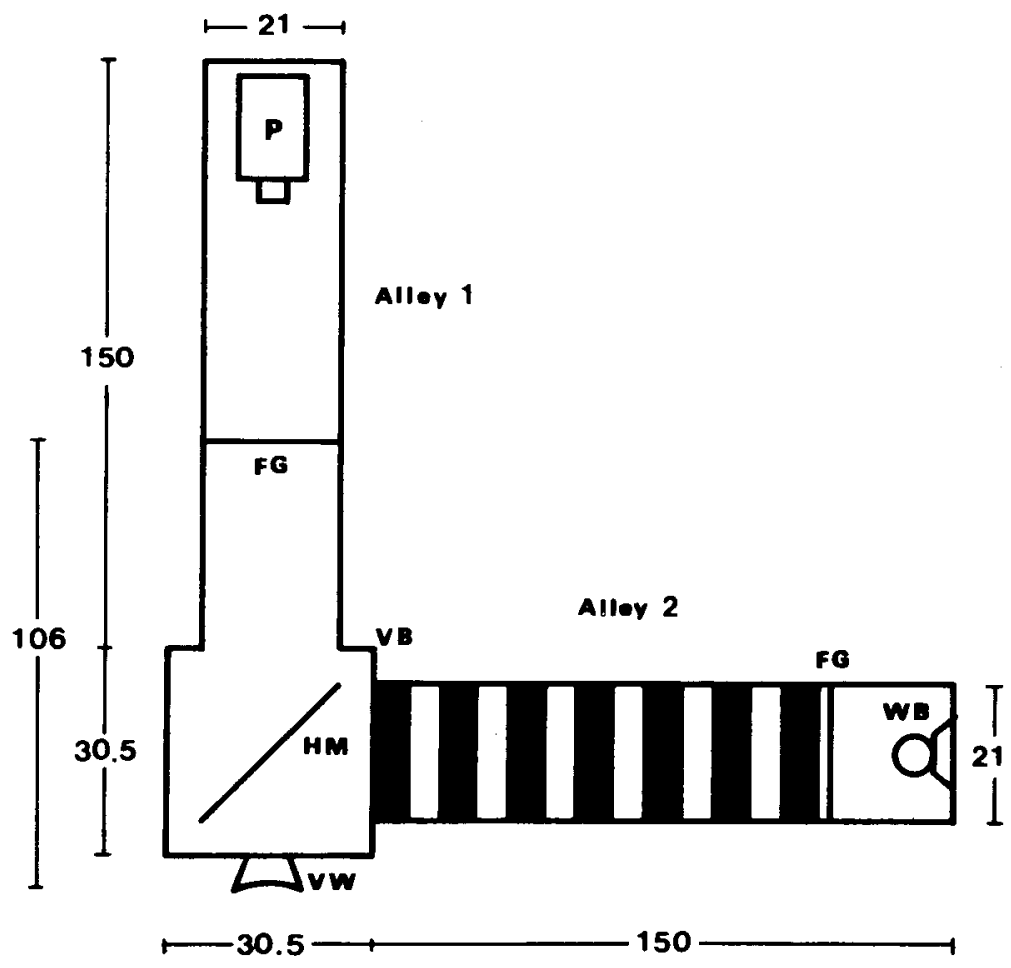

Figure 2. Schematic top-view diagram of the apparatus. P, projector; FG, frosted glass; VB, viewing box; HM, half-mirror; WB, white-light bulb; VW, viewing window. The size of the apparatus is given in centimeters.

alleys were formed by black drapery. A fall-type shutter was set in the viewing box to occlude the observer's view between stimulus presentations.

Design. The design of Experiment 1 involved a $3 \times 3 \times 2 \times 6$ factorial. The first factor was familiar size, with three stimulus objects-an Iwanami-bunko book, a Hi-lite cigarette package, and a 20-yen postage stamp. The normal widths of the book, package, and stamp are $10.5,5.7$, and $2.5 \mathrm{~cm}$, respectively, but the width of the image of the transparency on the frosted glass was $6.1 \mathrm{~cm}$ for any familiar stimulus target. Since targets with the same objective size were presented at the same viewing distance, the visual angle of the target was approximately equal to $.05755 \mathrm{rad}$ when observed through the viewing window.

The second factor was spatial cue condition: (1) MonocularA 1-mm-diam artificial pupil was inserted in the viewing window to allow the observer to view the familiar targets with her/his right eye only. In spite of the extremely reduced-cue situation, the observer received distance information from the accommodative resting state and/or accommodative convergence, as well as familiar size. (2) Binocular-The observer viewed the familiar objects with both eyes. The observer could make use of the natural combination of accommodation and convergence as well as familiar size. (3) Full-cue-The observer viewed the familiar objects binocularly in a fully illuminated alley. For this purpose, the black drapery forming the ceiling of alley $A_{2}$ was removed and the walls and the floor of the alley were illuminated by a white light bulb at the far end and by the fluorescent lamps on the ceiling of the experimental room. Alley $A_{1}$ remained the same. In addition to familiar size, the third condition provided many spatial cues, such as accommodation, convergence, binocular disparity, texture gradient, overlapping, and light and shadow.

The third factor was the instructions, "apparent" or "assumptive," given to the observers. The "apparent" instructions were: "I am going to present to you one at a time a series of familiar objects. I know that you often encounter them in your daily life.
But we are interested in apparent spatial properties of the familiar objects. Please forget all knowledge that you may have about the familiar objects. I want you to indicate both apparent size and apparent distance of each familiar target with verbal estimates expressed in meters, centimeters, or millimeters, or in some combination of them." The essential parts of the "assumptive" instructions were: "I am going to present to you one at a time a series of familiar objects. I know that you often encounter them in your daily life. We are interested in how familiar size influences the spatial properties of the familiar objects. Here familiar size means normal size of a particular object which is adequately known through visual or haptic experiences. Using knowledge that you may have about the familiar objects, please indicate both size and distance of each familiar target with verbal estimates expressed in meters, centimeters, or millimeters, or in some combination of them."

The fourth factor was presentation order of familiar targets. The permutation of the three targets produced six possible presentation orders. Five observers were assigned randomly to each of 36 combinations of spatial cue condition, instructions, and presentation order.

Procedure. The observer was seated in the proper position in front of the viewing box. After the experimenter was assured that the observer understood the instructions, he asked the observer to look at the familiar objects through the viewing window. Each of the three targets was presented for $30 \mathrm{sec}$ with a $30-\mathrm{sec}$ intertrial interval. The observer was asked to estimate both size and distance during presentation of a target. Judgments not reported during stimulus presentation were made immediately afterward from memory, since a target was never repeated for any observer.

\section{Results}

Separate $3 \times 2 \times 6 \times 3$ mixed-model analyses of variance, in which cue condition, instructions, and 
presentation order were between-subjects factors and familiar size was a within-subjects factor, were performed on size estimates and distance estimates. All statistical decisions were made with a significance level of $5 \%$. Since, in both analyses of variance, neither the main effect of presentation order nor its interaction with other factors was found to be significant, the scores were averaged over orders and observers for presentation in Tables 1 and 2, which show the results of size and distance estimates for 18 experimental conditions.

Size estimates. The size estimates were significantly different as a function of familiar size $[F(2,288)=$ $265.08, p<.001]$. The main effect of cue condition was also significant $[F(2,144)=3.35, p<.05]$, indicating that size estimates increase with increasing spatial cues. The main effect of instructions revealed that the assumptive instructions produced significantly larger size estimates than did the apparent instructions $[F(1,144)=4.66, p<.05]$.

The interaction of familiar size with instructions was significant $[\mathrm{F}(2,288)=62.72, \mathrm{p}<.001]$. The tests of simple main effects of the interaction revealed that for the stamp, the estimates were significantly larger under the apparent than under the assumptive instructions $[F(1,432)=19.37, p<.01]$; for the package, the difference between the two sets of instructions was not significant; for the book, the estimates reported under the assumptive instructions were significantly larger than those reported under the apparent instructions . $[F(1,432)=63.44, p<.001]$. Thus, under assumptive instructions, familiar size produced greater differentiation of size estimates.

The three-way interaction of familiar size, cue condition, and instructions was significant $[F(4,288)=$ $2.09, \mathrm{p}<.05$ ]. The tests of simple interaction effects of the three-way interaction indicated that the interaction of familiar size with cue condition was significant under the apparent instructions $[F(4,288)=3.59$, $\mathrm{p}<.01]$ but not significant under the assumptive instructions $(F<1)$. Furthermore, the tests of simple

Table 1

Means and Standard Deviations of Size Estimates (Judged Centimeters) of Three Familiar Targets as a Function of Type of Instructions and Spatial Cue Conditions

\begin{tabular}{|c|c|c|c|c|c|c|}
\hline & \multicolumn{3}{|c|}{ Apparent } & \multicolumn{3}{|c|}{ Assumptive } \\
\hline & Stamp & Package & Book & Stamp & Package & Book \\
\hline \multicolumn{7}{|c|}{ Monocular } \\
\hline $\begin{array}{l}\mathrm{M} \\
\mathrm{SD}\end{array}$ & $\begin{array}{l}2.6 \\
1.9\end{array}$ & $\begin{array}{l}5.2 \\
2.7\end{array}$ & $\begin{array}{l}7.3 \\
4.6\end{array}$ & $\begin{array}{r}1.7 \\
.5\end{array}$ & $\begin{array}{l}6.6 \\
2.4\end{array}$ & $\begin{array}{r}11.0 \\
3.7\end{array}$ \\
\hline \multicolumn{7}{|c|}{ Binocular } \\
\hline $\begin{array}{l}\mathrm{M} \\
\mathrm{SD}\end{array}$ & $\begin{array}{l}5.5 \\
5.2\end{array}$ & $\begin{array}{l}5.9 \\
2.8\end{array}$ & $\begin{array}{l}6.7 \\
3.4\end{array}$ & $\begin{array}{l}2.2 \\
1.0\end{array}$ & $\begin{array}{l}7.5 \\
2.9\end{array}$ & $\begin{array}{r}12.1 \\
3.2\end{array}$ \\
\hline \multicolumn{7}{|c|}{ Full-Cue } \\
\hline $\begin{array}{l}\mathrm{M} \\
\mathrm{SD} \\
\end{array}$ & $\begin{array}{l}5.1 \\
2.5 \\
\end{array}$ & $\begin{array}{l}7.1 \\
3.7 \\
\end{array}$ & $\begin{array}{l}8.8 \\
5.8 \\
\end{array}$ & $\begin{array}{l}2.6 \\
1.6 \\
\end{array}$ & $\begin{array}{l}6.3 \\
1.8 \\
\end{array}$ & $\begin{array}{r}11.6 \\
4.7 \\
\end{array}$ \\
\hline
\end{tabular}

Table 2

Means and Standard Deviations of Distance Estimates (Judged Meters) of Three Familiar Targets as a Function of Type of Instructions and Spatial Cue Conditions

\begin{tabular}{|c|c|c|c|c|c|c|}
\hline & \multicolumn{3}{|c|}{ Apparent } & \multicolumn{3}{|c|}{ Assumptive } \\
\hline & Stamp & Package & Book & Stamp & Package & Book \\
\hline \multicolumn{7}{|l|}{ Monocular } \\
\hline $\begin{array}{l}M \\
\text { SD }\end{array}$ & $\begin{array}{l}.57 \\
.61\end{array}$ & $\begin{array}{l}.96 \\
.53\end{array}$ & $\begin{array}{r}1.60 \\
.90\end{array}$ & $\begin{array}{l}.39 \\
.26\end{array}$ & $\begin{array}{l}1.46 \\
1.41\end{array}$ & $\begin{array}{l}2.80 \\
2.53\end{array}$ \\
\hline \multicolumn{7}{|l|}{ Binocular } \\
\hline $\begin{array}{l}\text { M } \\
\text { SD }\end{array}$ & $\begin{array}{r}1.05 \\
.64\end{array}$ & $\begin{array}{l}.94 \\
.38\end{array}$ & $\begin{array}{l}1.85 \\
1.93\end{array}$ & $\begin{array}{l}.49 \\
.50\end{array}$ & $\begin{array}{l}.82 \\
.39\end{array}$ & $\begin{array}{r}1.68 \\
.92\end{array}$ \\
\hline Full-Cue & & & - & & & \\
\hline $\begin{array}{l}\text { M } \\
\text { SD }\end{array}$ & $\begin{array}{l}.83 \\
.72\end{array}$ & $\begin{array}{l}.98 \\
.67\end{array}$ & $\begin{array}{l}1.47 \\
1.32\end{array}$ & $\begin{array}{l}.34 \\
.28\end{array}$ & $\begin{array}{l}.77 \\
.34\end{array}$ & $\begin{array}{l}1.91 \\
2.06\end{array}$ \\
\hline
\end{tabular}

main effects of the three-way interaction revealed that under the apparent instructions, the main effect of familiar size was significant for the monocular $[F(2,288)=25.25, \mathrm{p}<.001]$ and the full-cue conditions $[F(2,288)=15.09, p<.001]$, but not for the binocular condition, whereas, under the assumptive instructions, it was significant for any cue condition [for monocular, $F(2,288)=96.34, p<.001$; for binocular, $F(2,288)=107.54, p<.001$; for full-cue, $F(2,288)=90.54, p<.001]$. Thus, the effect of familiar size on size estimates is consistent and powerful under assumptive instructions, but inconsistent under apparent instructions. The remaining interactions were not significant.

Distance estimates. The main effect of familiar size was significant $[F(2,288)=75.23, p<.001]$. The main effects of cue condition and instructions were not significant.

The interaction of familiar size with instructions was significant $[F(2,288)=8.08, p<.001]$. The tests of simple main effects of the interaction revealed that, for the stamp, significantly larger estimates were reported under the apparent instructions than under the assumptive instructions $[F(1,432)=4.07$, $\mathrm{p}<.05]$; for the package, the difference between the apparent and the assumptive instructions was not significant; for the book, significantly larger estimates were reported under the assumptive instructions than under the apparent instructions $[F(1,432)=8.07$, $\mathrm{p}<.01]$.

The interaction of instructions with cue condition was also significant $[F(2,144)=3.79, \mathrm{p}<.05]$. This interaction was due to the monocular condition under the assumptive instructions, in which it was largely the distance estimates of the package and the book which contributed to the overall mean (see Table 2). The tests of simple main effects of the interaction indicated that the difference between the apparent and the assumptive instructions was significant only in the monocular condition $[F(1,144)=6.65, p<$ $.05]$. Thus, the two interactions suggest that assump- 
tive instructions amplify the effects of familiar size on distance estimates, in particular under the monocular condition.

\section{EXPERIMENT 2}

When the observer was forced, by the experimenter's instructions, to assume a particular attitude, Experiment 1 revealed an effect of attitude on the judgments of size and distance of familiar objects. If directive instructions are not given, what determines the observer's attitude? The most plausible variable would seem to be spatial cue condition. When spatial cues are reduced, it may be difficult to estimate the size and distance of an object without making assumptions or inferences about the visual world. Inversely, when the spatial cues are rich, the observers may take the apparent attitude, because the visual world is firmly constructed through informative cues, so that there is no reason to rely on assumptions or inferences in making judgments of size and distance. Thus, the purpose of Experiment 2 was to see how viewing attitude changes depending on spatial cue availability.

\section{Method}

Observers. Ninety students volunteered to serve as observers. All observers had normal or corrected visual acuity. None of them had participated in Experiment 1.

Apparatus, Design, and Procedure. All aspects of the apparatus were identical to those of Experiment 1. The design was similar to that of Experiment 1, except for the instructions given to the observers. All observers received "nondirective" instructions: "I am going to present to you one at a time a series of familiar objects. I know that you often encounter them in your daily life. I want you to indicate both size and distance of each familiar target with verbal estimates expressed in meters, centimeters, or millimeters, or in some combination of them. Please base your judgments on the way that you think most appropriate. There is no right way of making judgments; it is best to do what you believe is right."

Five observers were assigned randomly to each of 18 combinations of three spatial cue conditions and six presentation orders.

The procedure was identical to that of Experiment 1. After all judgments had been completed, the experimenter asked the observer to report the viewing attitude on which her/his judgments were based. In order to facilitate identification of the viewing attitude, a list of attitudes that were counterparts of the instructions read in Experiment 1 was provided. If the observer reported having taken neither viewing attitude, she/he was required to describe verbally the attitude that had been taken.

\section{Results}

Viewing attitude. The numbers of observers who took an apparent attitude were 9,14 , and 19 in the monocular, binocular, and full-cue conditions, respectively. The number of observers who took an assumptive attitude were 14,9 , and 7 in those same conditions, respectively. The majority of the remaining 18 observers described their way of judgment as a mixture of the apparent and the assumptive. For example, some observers reported that they took the apparent attitude for size estimates and the assumptive attitude for distance estimates, and other observers reported changing their attitudes depending on stimulus targets. A chi-square test was performed on a $2 \times 3$ contingency table with viewing attitude heading the columns and spatial cue condition heading the rows for the $\mathbf{7 2}$ observers who indicated that they had taken a single attitude. The results showed that the fewer the spatial cues, the more likely the observer was to take the assumptive attitude $\left[\chi^{2}(2)=\right.$ $9.58, \mathrm{p}<.01]$.

Size estimates. The size and distance estimates were divided into two subclasses, corresponding to the viewing attitude employed. Table 3 shows the means and standard deviations of the size estimates as a function of both spatial cue condition and viewing attitude. Note that the statistics are not necessarily based on an equal number of responses.

A one-way analysis of variance for repeated measures was performed on the size estimates from each of six combinations of cue conditions and viewing attitudes. The results showed that, with the assumptive attitude, the main effect of familiar size was significant under any cue condition [for monocular, $F(2,26)=34.08, p<.001$; for binocular, $F(2,16)=$ $57.18, \mathrm{p}<.001$; for full-cue, $F(2,12)=21.58, \mathrm{p}<$ $.001]$, whereas, with the apparent attitude, the main effect of familiar size was significant for binocular $[F(2,26)=3.86, p<.05]$ and full-cue conditions $[\mathrm{F}(2,36)=3.59, \mathrm{p}<.05]$.

Distance estimates. Table 4 summarizes the distance estimates, which were subjected to a one-way analysis of variance for repeated measures for each combination of cue conditions and viewing attitudes. The results showed that, with the assumptive attitude, the main effect of familiar size was significant for any cue condition [for monocular, $F(2,26)=$ $23.09, \mathrm{p}<.001$; for binocular, $F(2,16)=7.96, \mathrm{p}<$ .01 ; for full-cue, $F(2,12)=4.06, p<.05]$, whereas,

\section{Table 3}

Size Estimates (Judged Centimeters) Obtained From the Observers Taking the Apparent or Assumptive Attitude Under Three Spatial Cue Conditions

\begin{tabular}{|c|c|c|c|c|c|c|}
\hline & \multicolumn{3}{|c|}{ Apparent } & \multicolumn{3}{|c|}{ Assumptive } \\
\hline & Stamp & Package & Book & Stamp & Package & Book \\
\hline Monocular & \multicolumn{3}{|c|}{$(\mathrm{N}=9)$} & \multicolumn{3}{|c|}{$(N=14)$} \\
\hline $\begin{array}{l}\text { M } \\
\text { SD }\end{array}$ & $\begin{array}{l}2.4 \\
1.1\end{array}$ & $\begin{array}{l}4.6 \\
3.1\end{array}$ & $\begin{array}{l}3.3 \\
4.2\end{array}$ & $\begin{array}{r}1.7 \\
.6\end{array}$ & $\begin{array}{l}6.4 \\
2.1\end{array}$ & $\begin{array}{r}10.9 \\
5.6\end{array}$ \\
\hline Binocular & \multicolumn{3}{|c|}{$(N=14)$} & \multicolumn{3}{|c|}{$(\mathrm{N}=9)$} \\
\hline $\begin{array}{l}\mathbf{M} \\
\mathbf{S D}\end{array}$ & $\begin{array}{l}6.2 \\
2.5\end{array}$ & $\begin{array}{l}7.3 \\
2.7\end{array}$ & $\begin{array}{l}8.3 \\
4.3\end{array}$ & $\begin{array}{l}3.1 \\
2.4\end{array}$ & $\begin{array}{l}7.4 \\
1.8\end{array}$ & $\begin{array}{r}11.8 \\
4.4\end{array}$ \\
\hline Full-Cue & \multicolumn{3}{|c|}{$(\mathrm{N}=19)$} & \multicolumn{3}{|c|}{$(\mathrm{N}=7)$} \\
\hline $\begin{array}{l}\text { M } \\
\text { SD }\end{array}$ & $\begin{array}{l}4.6 \\
1.7\end{array}$ & $\begin{array}{l}5.9 \\
3.3\end{array}$ & $\begin{array}{l}5.6 \\
2.1\end{array}$ & $\begin{array}{r}2.5 \\
.8\end{array}$ & $\begin{array}{r}6.4 \\
.9 \\
\end{array}$ & $\begin{array}{r}10.3 \\
3.2 \\
\end{array}$ \\
\hline
\end{tabular}


Table 4

Distance Estimates (Judged Meters) Obtained From the Observers Taking the Apparent or Assumptive Attitude Under Three Spatial Cue Conditions

\begin{tabular}{cccccccr}
\hline & \multicolumn{3}{c}{ Apparent } & & \multicolumn{3}{c}{ Assumptive } \\
\cline { 3 - 4 } \cline { 5 - 6 } Stamp & Package & Book & & Stamp & Package & Book \\
\hline Monocular & & $(\mathrm{N}=9)$ & & & $(\mathrm{N}=14)$ \\
M & .37 & .63 & 1.68 & .35 & 1.46 & 2.11 \\
SD & .35 & .58 & 1.89 & .27 & .77 & 1.28 \\
Binocular & & $(\mathrm{N}=14)$ & & & $(\mathrm{N}=9)$ & \\
M & 1.54 & 1.39 & 2.44 & .50 & 1.06 & 1.50 \\
SD & 1.17 & 1.10 & 2.87 & .44 & .79 & .58 \\
Full-Cue & & $(\mathrm{N}=19)$ & & & $(\mathrm{N}=7)$ & \\
M & .67 & .63 & .84 & .63 & .91 & 1.51 \\
SD & .28 & .24 & .78 & .58 & .86 & .91 \\
\hline
\end{tabular}

with the apparent attitude, the main effect of familiar size was significant only for the monocular condition $[F(2,16)=4.54, p<.05]$.

Comparison between apparent and assumptive estimates. In order to compare the apparent and assumptive estimates in Experiment 2, a linear function was fitted to the size estimates from each observer as a function of familiar size. The left half of Table 5 indicates mean slopes and standard deviations for six combinations of cue conditions and viewing attitudes. For any cue condition, the slope was significantly steeper for the assumptive attitude than for the apparent attitude [for monocular, $t(21)=4.30$, $\mathrm{p}<.01$; for binocular, $\mathrm{t}(21)=5.25, \mathrm{p}<.01$; for fullcue, $t(24)=5.47, p<.01]$. In addition, the slopes were significantly larger than zero for the assumptive attitude [for monocular, $t(13)=6.81, p<.01$; for binocular, $t(8)=9.25, p<.01$; for full-cue, $t(6)=$ $4.69, \mathrm{p}<.01$ ], but were not larger than zero for the apparent attitude.

The right half of Table 5 indicates means and standard deviations of individual slopes of linear func-

Table 5

Means and Standard Deviations of Individual Slopes of Linear

Functions Fitted to Size and Distance Estimates Obtained With Apparent and Assumptive Attitudes Under Three Spatial Cue Conditions

\begin{tabular}{ccccc} 
& \multicolumn{2}{c}{ Size } & \multicolumn{2}{c}{ Distance } \\
\cline { 5 - 6 } & Apparent & $\begin{array}{c}\text { Assump- } \\
\text { tive }\end{array}$ & & \multicolumn{2}{c}{ Assump- } \\
& & & & \\
Monocular & & & & \\
M & .08 & 1.07 & .17 & .21 \\
SD & .42 & .57 & .22 & .15 \\
Binocular & & & & \\
M & .23 & 1.16 & .12 & .12 \\
SD & .41 & .35 & .25 & .06 \\
Full-Cue & & & & \\
M & .11 & .96 & .03 & .11 \\
SD & .27 & .47 & .09 & .12 \\
\hline
\end{tabular}

tions fitted to distance estimates as a function of familiar size. The slopes were not significantly different between viewing attitudes for any cue condition; for the assumptive attitude only, they were significantly larger than zero for the monocular [t(13) $=5.03, \mathrm{p}<.01]$ and the binocular conditions $[\mathrm{t}(8)=$ $5.53, \mathrm{p}<.01]$.

From the results of Experiment 2, it is clear that, with the apparent attitude, the effects of familiar size on size and distance estimates are weak and sporadic, whereas, with the assumptive attitude, the effects are consistently strong on size estimates for any cue condition and on distance estimates in reduced-cue conditions.

Consistency of estimates between Experiments 1 and 2. The scatter diagrams in Figure 3 illustrate the relationship between Experiments 1 and 2 for size (left) and distance estimates (right). In both diagrams, each data point indicates a mean for each combination of familiar targets, cue conditions, and viewing attitudes. The open circles represent the assumptive attitude; the filled circles represent the apparent attitude. The abscissa indicates the estimates in Experiment 1; the ordinate indicates the estimates in Experiment 2. One can see in both panels that the condition with the larger estimates in Experiment 1 tended to also produce larger estimates in the corresponding condition of Experiment 2. Pearson product-moment correlations showed a significant positive relation for size $(r=.89, p<.001)$ and distance estimates $(r=.83$, $\mathrm{p}<.001)$ between those experiments. These relatively high correlations were mainly due to the estimates obtained under the assumptive attitude: The correlations for the apparent and the assumptive attitudes were .43 and .99 for size estimates and .79 and .97 for distance estimates, respectively.

\section{DISCUSSION}

We obtained three main findings from the present study.

(1) When the observers were directed to take a particular viewing attitude (apparent or assumptive), no interaction of familiar size with cue condition was found for either size or distance judgments. This means that the differential responses for familiar objects do not increase as the number of spatial cues available decreases. The simplest form of the cueconflict hypothesis, as illustrated by the top panels of Figure 1, is not supported by this finding.

(2) The most effective variable activating the familiar-size cue was instructions, regardless of whether a specific viewing attitude was imposed by instructions or was taken spontaneously by the observer himself. This finding supported some form of a viewing-attitude hypothesis. In addition, this finding is consistent with the studies of Hastorf (1950), Baird (1963), and Park and Michaelson (1974), although 


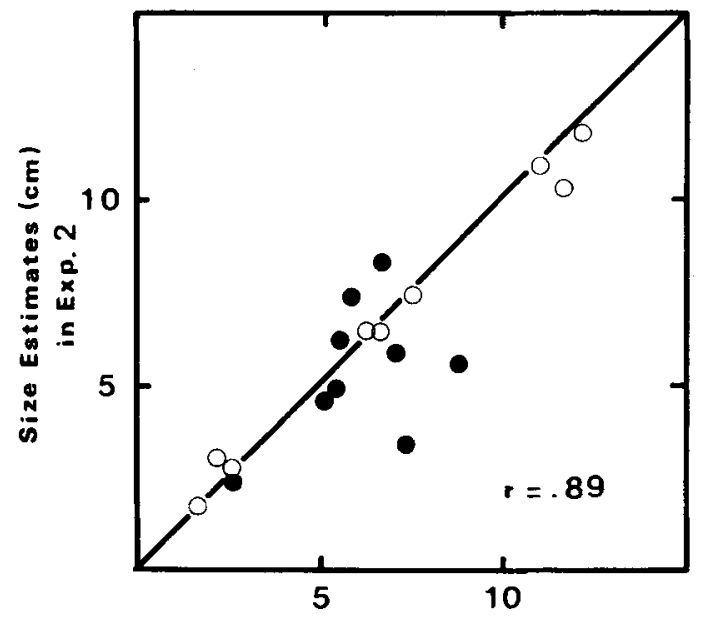

Size Estimates $(\mathrm{cm})$ in Exp. 1

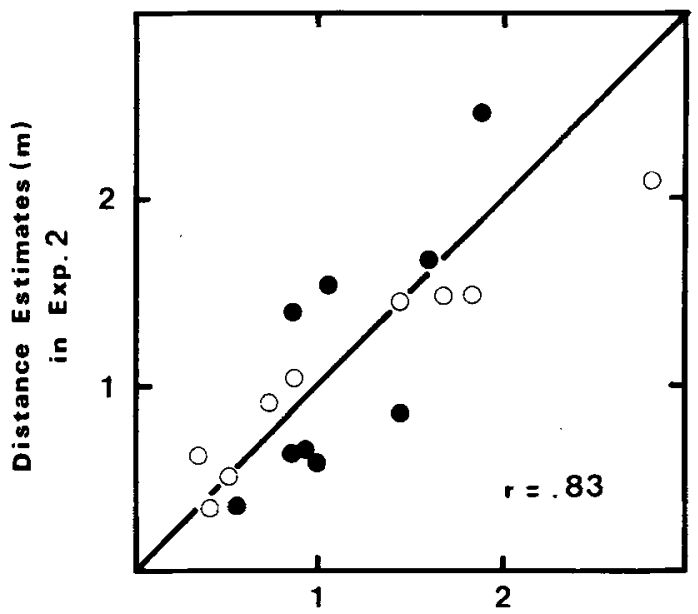

Distance Estimates $(\mathrm{m})$ in Exp. 1

Figure 3. Scatter diagrams of size (left) and distance (right) estimates illustrating the relations between Experiments 1 and 2. The open circles represent the assumptive attitude; the filled circles represent the apparent attitude.

not with those of Predebon et al. (1974). However, the two interactions found in Experiment 1-the three-way interaction of familiar size, instructions, and cue condition for size estimates and the two-way interaction of instructions with cue condition for distance estimates-indicate that cue conflict is effective in certain circumstances. Thus, the simplest form of the viewing-attitude hypothesis, as illustrated by the bottom panels of Figure 1, is not correct.

(3) When viewing attitude was not imposed by the instruction, the observer's viewing attitude reflected the number of conflicting cues: The apparent attitude gradually supplanted the assumptive attitude as spatial cues became available. This finding implies that viewing attitude can be considered as a dependent variable, although previous studies (Carlson, 1962; Carlson \& Tassone, 1971; Epstein, 1963) have treated it only as an independent variable that was operationally defined through the instructions. The results of Experiment 2 make it clear that cue information under nonspecific instructions influences the effects of familiar size through the formation of viewing attitude.

Generally, the effects of familiar size change as a function of viewing attitude and not of cue condition. The viewing attitude is either taken spontaneously by the observer himself or is formed involuntarily by the instructions. However viewing attitude is determined, it is evident that the overt responses produced under the assumptive attitude include more cognitive and fewer perceptual components than those produced under the apparent attitude. Therefore, the fact that familiar size is more effective under the assumptive attitude is due to the cognitive components of the overt responses of size and distance. It is also evident from both experiments that familiar size has an effect under the apparent attitude, although the effect here is smaller than it is under the assumptive attitude. This finding is not in agreement with the studies of Oyama (1974) and Mershon and Gogel (1975). However, it is premature to conclude that familiar size is a determiner of perceived size and distance, not only because the larger proportion of observers tend to take the assumptive attitude under the monocular condition, but also because there is a possibility that some observers did not interpret the apparent instructions as the experimenter had intended. As a result, an assumptive bias may have intruded into the judgments of size and distance under the apparent instructions (Mershon \& Gogel, 1975). In any event, it is difficult to resolve the verbal reports of size and distance into cognitive and perceptual components.

The assertion that the effects of familiar size may not be perceptual is also supported by the study of Higashiyama (1982), who attempted to determine the critical age at which familiar size begins to be used as a cue to size and distance judgments. The results indicated that familiar size, when formed through communicating the size information in the form of visual or haptic representation, proved very effective for 12-year-olds, partially effective for 9-year-olds, and ineffective for 7-year-olds. As compared with other pictorial cues, the critical age for familiar size is apparently late. For example, Wilcox and Teghtsoonian (1971) indicated the pictorial cues to depth to be effective for 9-year-olds, but ineffective for 3-year-olds; Benson and Yonas (1973) and Yonas and Hagen (1973) showed the critical age of the linearperspective or texture-gradient cue to be 3 years; Olson (1975) and Olson and Boswell (1976) found the overlapping cue to be available to 3 -year-olds. If 
utilization of familiar size did not need higher order intellectual activity, including cognitive inferences, the critical age for familiar size would be as early as that for the linear-perspective and overlapping cues.

\section{REFERENCES}

BAIRD, J. C. (1963). Relative and assumed size cues as determinants of size and distance perception. Journal of Experimental Psychology, 66, 155-162.

Benson, C., \& Yonas, A. (1973). Development of sensitivity to static pictorial depth information. Perception \& Psychophysics, 13, 361-366.

Carlson, V. R. (1962). Size-constancy judgments and perceptual compromise. Journal of Experimental Psychology, 63, 68-73.

Carlson, V. R., \& Tassone, E. P. (1971). Familiar versus unfamiliar size: A theoretical derivation and test. Journal of Experimental Psychology, 87, 109-115.

Colthe art, M. (1969). The influence of haptic size information upon visual judgments of absolute distance. Perception \& Psychophysics, 5, 143-144.

Colthenrt, M. (1970). The effect of verbal size information upon visual judgments of absolute distance. Perception \& Psychophysics, 9, 222-223.

Epste in, W. (1963). Attitude of judgment and the size-distance invariance hypothesis. Journal of Experimental Psychology, 66, 78-83.

Fitzpatrick, V., Pasnak, R., \& Tyer, Z. E. (1982). The effect of familiar size at familiar distance. Perception, 11, 85-91.

GoosL, W. C. (1969). The effect of object familiarity on the perception of size and distance. Quarterly Journal of Experimental Psychology, 21, 239-247.

GooEL, W. C. (1976). An indirect method of measuring perceived distance from familiar size. Perception \& Psychophysics, 20, 419-429.

Goael, W. C. (1977). An indirect measure of perceived distance from oculomotor cues. Perception \& Psychophysics, 21, 3-11.

Gooes, W. C. (1981). The role of suggested size in distance perception. Perception \& Psychophysics, 30, 149-155.
Gogel, W. C., \& Newton, R. E. (1969). Perception of off-sized objects. Perception \& Psychophysics, 5, 7-9.

Hastonf, A. H. (1950). The influence of suggestion on the relationship between stimulus size and perceived distance. Journal of Psychology, 29, 195-217.

Higashiyama, A. (1982). [The effects of familiar-size cue on children's judgments of size and distance] (in Japanese). Japanese Journal of Psychology, 53, 259-265.

Mershon, D. H., \& Gogel, W. C. (1975). Failure of familiar size to determine a metric for visually perceived distance. Perception \& Psychophysics, 17, 101-106.

OLson, R. K. (1975). Children's sensitivity to pictorial depth perception. Perception \& Psychophysics, 17, 59-64.

Olson, R. K., \& Boswell, S. L. (1976). Pictorial depth sensitivity in two-year-old children. Child Development, 47, 1175-1178.

ONo, H. (1969). Apparent distance as a function of familiar size. Journal of Experimental Psychology, 79, 109-115.

Oyama, T. (1974). Perceived size and perceived distance in stereoscopic vision and an analysis of their causal relations. Perception \& Psychophysics, 16, 175-181.

Park, J. N., \& Michaelson, G. J. (1974). Distance judgments under different size-information conditions. Perception \& Psychophysics, 15, 57-60.

Predebon, G. M., Wenderoth, P. M., \& Curthoys, I. S. (1974). The effects of instructions and distance on judgments of off-size familiar objects under natural viewing condition. American Journal of Psychology, 84, 425-439.

Schiffman, H. R. (1967). Size-estimation of familiar objects under informative and reduced conditions of viewing. American Journal of Psychology, 80, 229-235.

Wilcox, L., \& TEGHTSOONIAN, M. (1971). The control of relative size by pictorial depth cues in children and adults. Journal of Experimental Child Psychology, 11, 413-429.

Yonas, A., \& Hagen, H. (1973). Effects of static and motion parallax depth information on perception of size in children and adults. Journal of Experimental Child Psychology, 15, 254-265.

(Manuscript received June 28, 1983;

revision accepted for publication February 10, 1984.) 